\title{
Radon emanation from drinking water samples of Nineveh province (IRAQ)
}

\author{
Laith Ahmed Najam ${ }^{1, ~ *}$, Nada Fathil Tawfiq², Enas Mohmad Younis ${ }^{1}$ \\ ${ }^{1}$ Department of Physics, College of Science, Mosul Univ., Mosul, Iraq \\ ${ }^{2}$ Department of Physics, College of Science, Al-Nahrain Univ., Baghdad, Iraq
}

Email address:

Prof.lai2014@gmail.com (L. A. Najam)

\section{To cite this article:}

Laith Ahmed Najam, Nada Fathil Tawfiq, Enas Mohmad Younis. Radon Emanation from Drinking Water Samples of Nineveh Province (IRAQ). American Journal of Modern Physics. Vol. 3, No. 6, 2014, pp. 257-260. doi: 10.11648/j.ajmp.20140306.20

\begin{abstract}
The study include measurements of radon concentration in water samples for a total of eleven selected locations from Nineveh province. The natural exposure method using CR-39 track detector and the sealed cuptechniquewere chosen for analysis of radon concentration. Radon content in water samples of the study area ranges from 17.4Bq/l in Talskuf to 36.1 Bq/1 in Sad Al-Mosul with an average value $26.37 \mathrm{~Bq} / \mathrm{l}$, all measured ${ }^{222} \mathrm{Rn}$ activity concentrations in water are below the European Commission recommended level for radon in drinking water of $100 \mathrm{~Bq} / \mathrm{l}$.The results of the annual effective dose ranged from $64 \mu \mathrm{Sv} / \mathrm{y}$ in Talskuf to $132 \mu \mathrm{Sv} / \mathrm{y}$ in Sad Al-Mosul, the total annual effective dose in $54.54 \%$ locations of the studied area are found to be within the safe limit $(0.1 \mathrm{mSv} /$ year $)$ recommended by World Health Organization and EU Council and $45.45 \%$ locations are exceeding the annual effective dose limit of $0.1 \mathrm{mSv} / \mathrm{y}$.
\end{abstract}

Keywords: Radon Emanation, Nineveh Province, Track density, Annual Effective Dose

\section{Introduction}

Radon is the heaviest gas in the natural decay series of uranium, thorium and actinium. ${ }^{222} \mathrm{Rn}$ (usually called radon), since it can decay to solid $\left({ }^{218} \mathrm{~Pb},{ }^{214} \mathrm{~Pb},{ }^{214} \mathrm{Bi},{ }^{214} \mathrm{Po}\right)$ in the lung is the most important isotope for human health. It has a half-life of 3.825 days and is ubiquitous in the environment. ${ }^{222} \mathrm{Rn}$ emanates from soil and rock, which is also the main source of radon in the atmosphere [1].

Although radon is chemically inert and electrically uncharged, when resulting atoms called radon progeny, are formed, they are electrically charged and can attach themselves to tiny dust particles in indoor air [2].

Radon and its daughter products are the major of radiation exposure and recognized as one of the health hazards from mankind [3].

The earth is radioactive since its creation. The inhalation and ingestion of these radio nuclides above the permissible level becomes a health hazard. Therefore, concern of the monitoring of these radio nuclides in the environs is increasing at all levels, due to their harmful effects [4].

Most of radon that enters building comes directly from soil that in contact with beneath the basement or foundation. Radon is also found in ground water and will enter a home whenever this water is used. In many situations such as showering, washing, clothes and flushing toilets,

Radon is released from the water and mixes with indoor air. Thus, radon from water contributes to the total inhalation risk associated with radon in indoor air [5].

However a very high level of radon in drinking water can also lead to a significant risk of the stomach and gastrointestinal cancer [6].

Knowledge of the levels of radon in each source including household water, particular water from ground sources is necessary to protect public from consequences of excessive exposure to radiations mainly from the lung cancer. Radon was measured in water in many parts of the world, mostly for assessing the risk due to consumption of drinking water [7-9].

Water is an indispensable natural resource on earth. Approximately $71 \%$ of the earth's surface is covered with water. Fresh water is found as underground water in large reservoirs surrounded by rock called aquifers and surface water. It is an essential and vital component for survival of all the living beings. There is a great demand for pure water because the groundwater and surface water are highly polluted due to urbanization and industrialization. Out of the total amount of global water, only $2.4 \%$ is distributed on the main land, of which only a small portion can be utilized as fresh water. Ground water is the principal source of drinking 
water in both rural and urban parts of India. The quality of ground water vary with geology of the particular area, depth of water table, seasonal changes, composition of dissolved salts depending upon sources of salt and surface environment. Ground water is a weak electrolyte containing various elements and their associated radicals in ionic equilibrium. The major cations determined are calcium, magnesium, sodium and potassium [10].

The aim of this work is to determine the radon concentrations in water used for drinking andother purposes by SSNTD technology in order to estimate the corresponding radiation dose received by peopleslived inNineveh provinceand to assess the contribution from radon in water to the total environmental radon level.

\subsection{Geology of Area}

The area of the study is Nineveh province. Nineveh province is located in northern Iraq and its capital city is Mosul and the geographic coordinates of Mosul is between latitude $37^{\circ} 1^{\prime} 45.51^{\prime \prime} \mathrm{N}$, longitude $42^{\circ} 21^{\prime} 40.14 " \mathrm{E}$ and latitude $35^{\circ} 25^{\prime} 12.78^{\prime \prime} \mathrm{N}$, longitude $42^{\circ} 47^{\prime} 31.17^{\prime \prime} \mathrm{E}$, while the height above sea level ranges between $202 \mathrm{~m}-364 \mathrm{~m}$. Water samples were collected from approximately all regions of Nineveh as illustrated in Fig. 1.

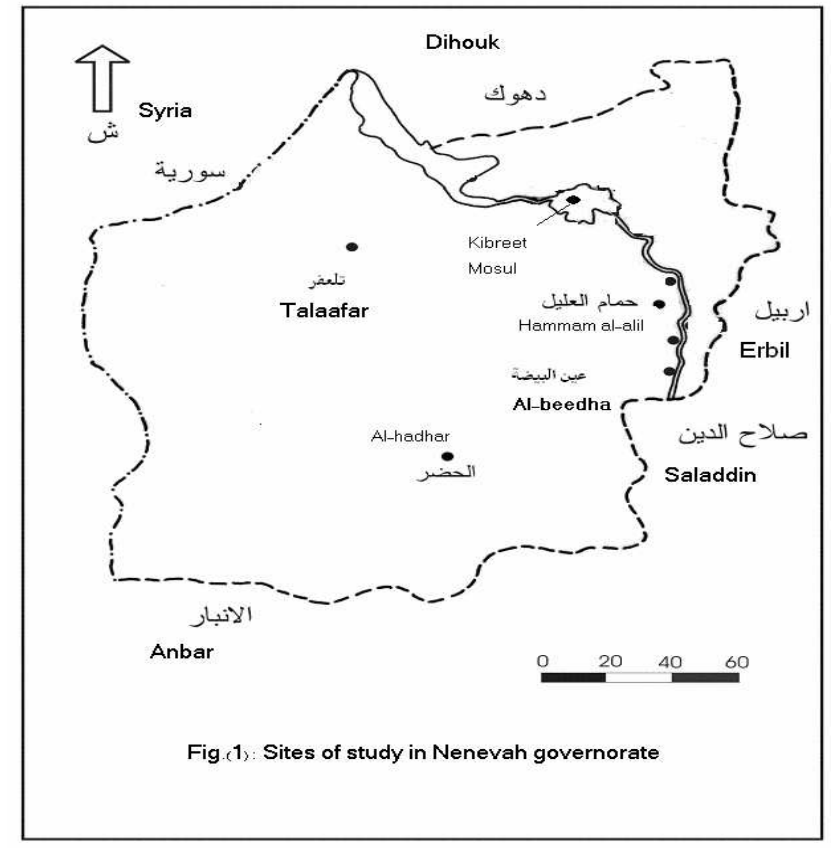

Fig 1. Map of Nineveh Province showing the area surveyed during the present investigations

\section{Materials and Methods}

Sample collection and analysis for ${ }^{222} \mathrm{Rn}$ activity

Groundwater wells and surface water streams and rivers samples from eleventh different selected locations in northern sector at the Iraq of Nineveh sited in Fig. 1, during May 2013 for analysis of radon concentration.

The natural exposure method using the sealed cup technique was used for radon estimation and CR-39 track Detectors used for the measurements of radon concentration in water [12]. A $100 \mathrm{ml}$ water samples were poured into $8.5 \times 6 \mathrm{~cm}$ cylindrical containers Fig.2. CR-39, $1.5 \times 1.5 \mathrm{~cm}^{2}$ small pieces were fixed by double-stick tape at the bottom of container's cover. The containers then covered, sealed and left for 60 days to irradiate the films with alpha particles emitted from radon. After 90 days of irradiation the detectors will be etched with $\mathrm{NaOH}$ solution with conditions7 hours at $60{ }^{\circ} \mathrm{C}$. The detectors then washed many times by distilled water and dried. The numbers of tracks due to alpha particles interaction are counted with an optical microscope with magnification of $400 \mathrm{X}$. The track density $\rho$ is proportional to the radon activity concentration $C_{\mathrm{Rn}}$.

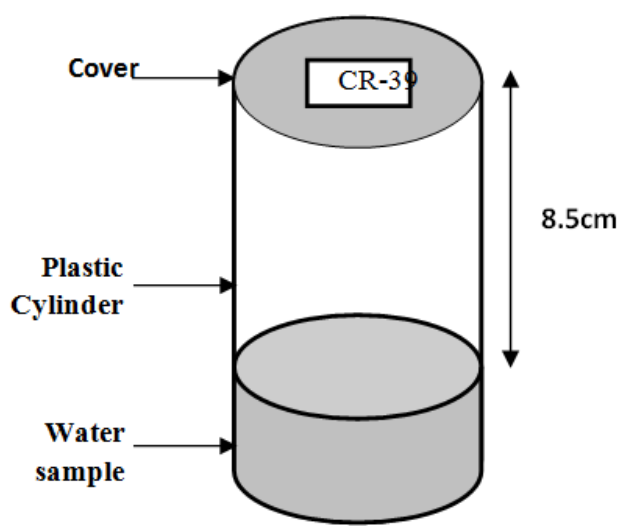

Fig 2. The cylindrical plastic containers used for the natural exposure Technique used for radon determination in water.

\section{Calculations}

\section{Radon concentrations}

Radon concentrations in the water samples were determined using the formula [13];

$$
C_{\mathrm{Rn}, \mathrm{x}}=C_{\mathrm{Rnc}} \cdot\left(\rho_{\mathrm{x}} / \rho_{\mathrm{c}}\right)
$$

where the subscripts $\mathrm{x}$ and $\mathrm{c}$ stand for the unknown and the standard, respectively; $\mathrm{C}_{\mathrm{Rn}}$, is the radon content; $\rho \mathrm{x}$ and $\rho \mathrm{c}$ are the densities of the tracks for unknown and standard.

The relation of uranium concentration and track densities in standard samples are shown in Fig.3 [11].

Estimation of annual effective dose by ingestion

Radon enters human body through ingestion and through inhalation as radon is released from water to indoor air. Therefore, radon in water is a source of radiation dose to stomach and lungs.

The estimated annual effective dose by ingestion was calculated because of habitual consumption of water by dwellers. It was computed using the formula below: [14]

$$
\mathrm{D}_{\mathrm{W}}=\mathrm{Cw} \cdot \mathrm{CRw} \cdot \mathrm{Dcw}
$$

where $D_{W}$ is the annual effective dose equivalent $\left(\mu \mathrm{Svy}^{-1}\right)$ due to ingestion of radionuclide from the consumption of water; $\mathrm{Cw}$ is the concentration of $\mathrm{Rn}-222$ in the ingested drinking water $\left(\mathrm{Bql}^{-1}\right)$; $\mathrm{CRw}$ is the annual intake of drinking 
water $\left(1 \mathrm{y}^{-1}\right)$, and Dcw is the ingested dose conversion factor for ${ }^{222} \mathrm{Rn}\left(\mathrm{SvBq}^{-1}\right)$. A dose conversion factor of $5 \times 10^{-}$ ${ }^{9} \mathrm{SvBq}^{-1}$ was used as suggested by the United Nations Scientific Committee on the Effects of Atomic Radiation (UNSCEAR) [15]. Annual effective dose due to intake of $\mathrm{Rn}-222$ from drinking water is calculated considering that an adult. An average of $730 \mathrm{~L}$ water was estimated annually for an adult (Age > 18y) [16]. The conversion factor that we used for our calculation was $\mathrm{D}=14.4 \mu \mathrm{Sv} / \mathrm{kBq}^{222} \mathrm{Rn}[17]$.

Results and Discussion

The results of ${ }^{222} \mathrm{Rn}$ measurements in water in the Nineveh Province at the north of Iraq using CR-39 track detector are shown in Table 1 and as graphically represented in Fig.4.The values in samples from Nineveh Province range from $17.4 \pm$ 0.8 to $36.1 \pm 1.2 \mathrm{~Bq} / \mathrm{l}$ with an average value of $26.37 \pm 6.57$ $\mathrm{Bq} / \mathrm{l}$. In Nineveh Province the maximum values of radon concentration are found in water at Sad Al-Mosul and Hemam Al-Aleel, whereas the minimum values are found at Talskuf region. High concentrations obtained may be attributed to the geology of the study area which is more concentrations of radium-226 and other radionuclide belonging to the uranium and thorium series. Radon in water depends on the local geology, radium and uranium dissolved in water and hydro geological conditions and rock of the aquifer and the presence of thrusts, faults and shears which facilitate upward migration of radon gas [18-19]

The health and environmental protection agencies (EPA) have recommended a safe limit of radon in drinking water for human beings, it has proposed that the allowed maximum contamination level for radon concentration in water is 11 $\mathrm{Bq} / \mathrm{l}$ [20]. Radon concentration in water samples from the study area was found to be higher than the recommended value [20].

The UNSCEAR has suggested a value of radon concentration in water for human consumption between 4 and $40 \mathrm{~Bq} / \mathrm{l}$. The values of radon concentration in water are within the safe limit recommended by UNSCEAR[15,21].When the recorded radon concentration values were compared with the European Commission recommendations on the protection of the public against the exposure to radon in drinking water supplies, which recommends the action level of $100 \mathrm{~Bq} / 1$ for public water supplies [21], all the recorded values of the samples were found to be well below the action level and hence safe for drinking purposes.

The estimated annual effective dose ranged from 64 to 132 $\mu \mathrm{Sv} / \mathrm{y}$ with average of $96.3 \pm 24.0 \mu \mathrm{Sv} / \mathrm{y}$ are shown in Table 1 , and as graphically represented in Fig.5. Since the effective

dose depends on the mean radon concentrations, the areas which recorded high concentrations also had high values of annual effective dose.

According to the World Health Organization (WHO) guidance level in drinking water on intake of radionuclides, the annual effective dose due to intake of radionuclides should not exceed $0.1 \mathrm{mSv} / \mathrm{y}(100 \mu \mathrm{Sv} / \mathrm{y})$ (WHO, 2004).This shows that the calculated annual effective dose due to ingestion of radon in water to any individual adult in the population group living in ( Al-Sahel Al-Aemen,Hemam AlAleel, Al-Sahel Al-Aeser, Talaefar and Sad Al-Mosul) is slightly higher than the average value set by the WHO [22].The present results show that the annual effective dose in (Rabiaa, Al-Hamadania, Talskuf, Sanjar, Al-Kayra and Zemar) and the average annual effective dose not exceeding the annual effective dose limit of $0.1 \mathrm{mSvy}^{-1}$ [22].

All measured ${ }^{222} \mathrm{Rn}$ activity concentrations in water are below the European Commission recommended level for radon in drinking water of $100 \mathrm{~Bq} / 1[21]$. These levels are set to represent a concentration that does not result in any significant risk to health over a life time's drinking water.

\section{Conclusion}

The observed values of radon concentration in water of different areas of Nineveh province are well exceed the maximum contamination limit recommended by the EPA of $11 \mathrm{~Bq} / \mathrm{l}$, and All measured ${ }^{222} \mathrm{Rn}$ activity concentrations in water are below the European Commission recommended level for radon in drinking water of $100 \mathrm{~Bq} / \mathrm{l}$.

The total annual effective dose in $54.54 \%$ locations of the studied area are found to be within the safe limit $(0.1 \mathrm{mSv} /$ year $)$ recommended by World Health Organization and EU Council and $45.45 \%$ locations are exceeding the annual effective dose limit of $0.1 \mathrm{mSv} / \mathrm{y}$.

Table 1. Radon Concentration and Annual Effective Dose in Drinking Water

\begin{tabular}{llll}
\hline Symbols & Sample Location & Radon Concentration Bq/l & Annual Effective Dose $(\boldsymbol{\mu S v} / \mathbf{y})$ \\
\hline $\mathrm{a}_{1}$ & Rabiaa & $18.1 \pm 0.9$ & 66 \\
$\mathrm{a}_{2}$ & Al-Sahel Al-Aemen & $30.1 \pm 1.2$ & 110 \\
$\mathrm{a}_{3}$ & Hemam Al-Aleel & $35 \pm 1.1$ & 128 \\
$\mathrm{a}_{4}$ & Al-Hamadania & $20.3 \pm 1.02$ & 74 \\
$\mathrm{a}_{5}$ & Talskuf & $17.4 \pm 0.8$ & 64 \\
$\mathrm{a}_{6}$ & Sanjar & $21.5 \pm 1.1$ & 78 \\
$\mathrm{a}_{7}$ & Al-Sahel Al-Aeser & $30.1 \pm 1.2$ & 109.8 \\
$\mathrm{a}_{8}$ & Al-Kayra & $21.4 \pm 0.97$ & 78 \\
$\mathrm{a}_{9}$ & Talaefar & $33 \pm 1.8$ & 120 \\
$\mathrm{a}_{10}$ & Sad Al-Mosul & $36.1 \pm 1.2$ & 132 \\
$\mathrm{a}_{11}$ & Zemar & $27.13 \pm 0.9$ & 99 \\
& Average & $26.37 \pm 6.57$ & $96.3 \pm 24.0$ \\
\hline
\end{tabular}




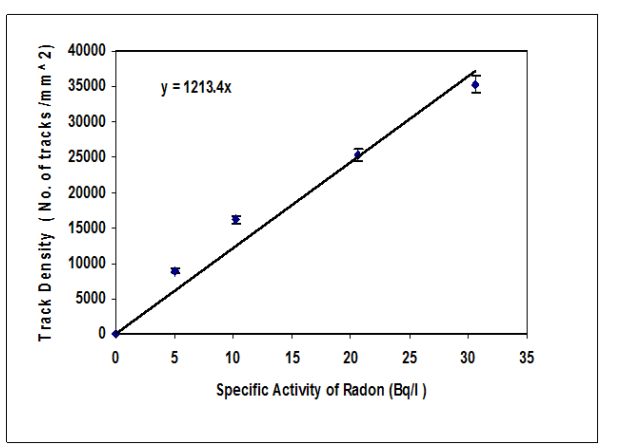

Fig 3. Track density versus radon concentration in standard samples

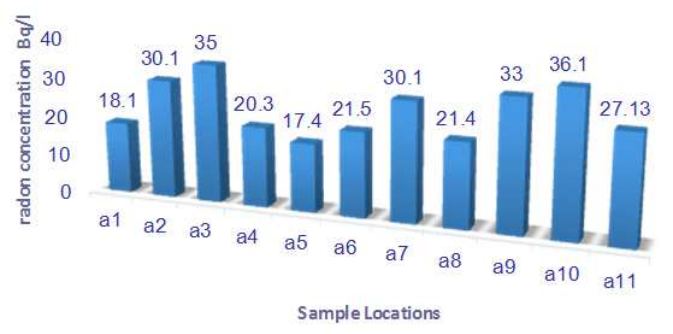

Fig 4. Radon concentrations in water samples

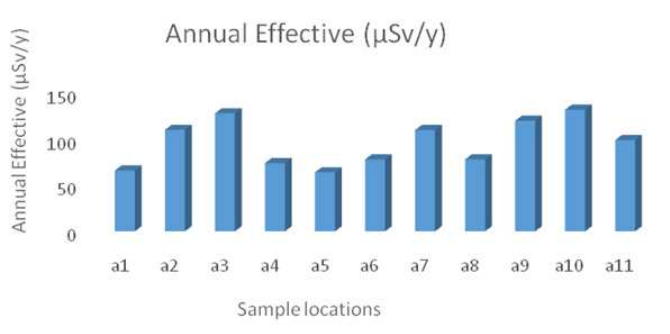

Fig 5. Annual effective dose by ingestion

\section{References}

[1] EnsKapdan and NesrinAltinosy (2014), Indoor radon levels in work places of Adapazari, north -western Turkey, J. Earth Syst. Sci., 123(1), 213-217.

[2] National Research Council, (1999), Health Effects of Exposure to Radon: BEIR VI. Washington, DC: The National Academies Press.

[3] Ajay Kumar and Kaur, Amanjot, Kaur,(2014), A study of radon concentration in water and radon exhalation rate in soil samples belonging to Kapurthala district, Punjab, India, Advances in Applied Science Research ,5(1),43-47.

[4] Agency for toxic substances and Diseases Registry (ATDSR), (1999) Report Tp-90229, Atlanta USA.

[5] VikasDuggal, RohitMehra and Asha Rani,(2013), Analysis of radon concentration in drinking water in Hanumangarh district of Rajasthan, India, Radiation Protection and Environment,36(2),65-70.

[6] Zhuo W., Lida T., Yang X.,(2001), Occurrence of ${ }^{222} \mathrm{Rn},{ }^{226}$ $\mathrm{Ra},{ }^{228} \mathrm{Ra}$ and $\mathrm{U}$ in groundwater in Fujian Province ,J. Environ Radioact 53(1), 111-120 .
[7] Rani A., Mehra R., Duggal V., (2013), Radon monitoring in groundwater samples from some areas of Northern Rajasthan,India using a RAD7 detector, Radiat Protect Dosimetry, 153, 496-501.

[8] Duggal V., Mehra R., Rani A.,(2013), Determination of ${ }^{222} \mathrm{Rn}$ level in groundwater using a RAD7 detector in Bathinda district Punjab India, Radiat. Prot.Dosimetry,156(2),239-245

[9] RamolaRc, RawatRB,Kandari MS and Choubey V.M., (1997), Measurement of radon in drinking water and indoor air, Radiat. Prot. Dosimetry, 74(1-2), 103-106.

[10] Srilatha M.C.,Rangaswamy D.R. and Sannappa J.J.,(2014), Studies on concentration of Radon and Physicochemical parameters in groundwater around Rammanagara and Tumkur districts ,Karnataka, India, International journal of Advanced Scientific and Technical Research,2(1),641-660.

[11] Nada. F.Tawfiq, (2013), Uranium and radon concentration in ground water in Aucashat city (Iraq) and the associated health effects, Advances in Applied Science Research, 4(3), 167171.

[12] Misdaq M. A, Satif C, (1995), Journal Radioanalytical and Nuclear Chemistry, 198(1), 179-189.

[13] Fleischer R.L., Price P.B., Walker R.M., (1975), Nuclear Tracks in Solids, Principles and Applications. University of California Press, Berkeley, (USA).

[14] Alam M. N., M. I. Chowdhry, M. Kamal, S. Ghose, M. N. Islam Waruddin M. A., (1999), Radi. Prot.Dosim., , 82,207.

[15] United Nations Scientific Committee on the effects of Atomic Radiation, Sources, Effects and Risks of Ionizing Radiation. (1988), Report to the General Assembly, pp. 2479. United Nations, New York.

[16] Cevik U, Damla N, Karahan G, et al.( 2006), Natural radioactivity in tap waters of eastern black sea region of Turkey. Radiation Protection Dosimetry118: 88-92.

[17] Yu K. N., Guan Z. J., Stokes M. J. Young E. C. M., (1994), Applied Radiation and Isotopes, 45,809.

[18] Choubey VM, Ramola RC (1997), Correlation between geology and radon levels in groundwater, soil and indoor air in Bhilangana Valley, Garhwala Himalaya, India.EnvironGeol 32 (4): 258-262.

[19] Kuntsson G, Olofasson B., (2002) Radon content in groundwater from drilled wells in the Stockholm regions of Sweden. NGU-bulletin, pp.79-85.

[20] United States Environmental Protection Agency, (1991), Federal Register 40 Parts 141 and 142 National Primary Drinking Water Regulations; Radionuclides: Proposed Rule. Washington, DC: US Government Printing Office.

[21] European Commission. Commission recommendation of 20th December 2001 on the protection of the public against exposure to radon in drinking water. 2001. 2001/982/Euratom, L344/85, Official Journal of the European Commission.

[22] WHO (World Health Organization), (2004), Guidelines for Drinking Water Quality. 3rd Edn.,Recomm and ations, Geneva, ISBN: 92-45-154638 7. 